\title{
Store Location in Shopping Centers: \\ Theory and Estimates
}
Authors
Charles C. Carter and Kerry
D. Vandell

Abstract

This paper develops a formal theory of store location within shopping centers based on bid rent theory. The bid rent model is fully specified and solved with the objective function of profit maximization in the presence of comparative, multipurpose and impulse shopping behavior. Several hypotheses result about the optimal relationships between store types, sizes, rents, sales, and distances from the mall center. The hypotheses are tested and confirmed using data from a sample of 689 leases in eight regional and super-regional shopping centers, suggesting that a bid rent explanation is consistent with observed location patterns in malls.

Since 1990 some interesting non-location studies on shopping centers have explored the microeconomic foundations of lease price discrimination and store space allocation (Benjamin, Boyle and Sirmans, 1992; Brueckner, 1993; and Pashigan and Gould, 1998). All of these studies are based on the concept of interstore externalities; thus, any expansion of these studies to include location aspects would necessarily be based on agglomeration economies.

During the same timeframe, two applied circulation studies on customer traffic in shopping centers suggested use of bid rent theory to explain the locational characteristics of stores (Sim and Way, 1989; and Brown, 1991). Both articles suggested that a bid rent-style model would appropriately describe customer circulation in a regional or super-regional shopping center. A seminal working paper in the economics tradition also suggested a bid rent foundation be used to explain store location in shopping centers (Fisher and Yezer, 1993).

The current paper deals with the spatial aspects of shopping centers using bid rent theory, leaving the more difficult aspects of agglomeration economies for others. ${ }^{1}$ What is important and novel is the treatment of inter-store location in the shopping center in the context of urban spatial structure.

Pashigan and Gould (1998) suggest that the failure or inability to internalize externalities contributed to the decline of the central business district (CBD) and the rise of shopping centers. So shopping centers are worthy of study generally if for no other reason than for the dramatic way they have reshaped retailing. Post- 
World-War II suburbanization, economic growth and mass ownership of the automobile were necessary before shopping centers could thrive. But shopping centers experienced a sudden dramatic rise in growth when developers became convinced of the success of the enclosed mall concept in the late 1950s and early 1960s. By 1989, shopping centers captured $55.2 \%$ of all non-automotive retail sales in the United States.

The goals of this article are to provide economic explanations for location patterns of non-anchor stores in regional and non-regional shopping centers, relying on bid rent theory to explain optimal store location. Several issues were immediately recognized as complicating factors that needed to be dealt with. These included (1) the fact that Alonso's bid rent model operates only in perfectly competitive markets and (2) the transportation costs of the bid rent model are absent in the context of shopping centers.

This article proceeds as follows. First, the background literature on the shopping center industry is presented, which is followed by a discussion of the formal bid rent model as modified for a shopping center context. Next, testable hypotheses regarding relative locations of stores by type, size, rent, and sales are proposed for mall tenants that maximize profits for both tenants and the mall developer. Hedonic equations based on Rosen (1974) are then estimated to determine the economic impact of mall centers on store rent. The empirical tests employ a shopping center database containing 849 observations. The empirical results then provide strong support for the theory that stores' location and size follow Alonso's basic bid rent pattern. Finally, concluding comments are presented.

\section{Industry Wisdom and the Nature of Shopping Centers}

Since shopping centers internalize externalities through their leasing arrangements, and the process reveals itself through rent discrimination and mall space allocation, further manifestation of the process should be discoverable, including spatial evidence.

The optimal decisions of the shopping center developer as the "perfectly discriminating monopolist" should be revealed through other spatial characteristics, particularly those related to store location. Characteristics of stores, i.e., size, sales per square foot and rent per square foot, as they relate to location, should be important. Secondarily, size, shape and general layout of shopping centers place constraints on store location and therefore are also relevant to overall store location.

\section{Mall Configuration}

The most common configuration for shopping centers is linear. Parking is provided in the rear, at the sides, or in front. Commonly, most or all of the area around regional or super-regional centers will be devoted to parking, unless a multi-level 
parking structure is provided for customer use. ${ }^{2}$ The presence of two anchor ${ }^{3}$ stores, each placed at an end of the center, is typically considered optimal so that they will draw customer traffic through the center. A large linear center, such as a regional center, will have separated anchors; for example, the principal anchor in the middle with two smaller anchors at the ends (Darlow, 1972; Northern and Haskoll, 1977; Beddington, 1982; Maitland, 1985; Brown, 1991; Mulvihill, 1992; and ULI, 1999). Regional and super-regional centers almost always have a central courtyard area reserved for food service, and this area is normally contained near the center of the mall.

Large, regional and super-regional centers are more likely to be nonlinear in shape. Comfortable walking distance between anchors in these centers is about 400 feet, though some successful malls have had walking distances between anchors of 750 feet (ULI, 1999). An obvious reason for a non-linear layout for a center is to make fullest use of a square site. Another reason for the use of non-linear shapes is "to restrict the length of a center that would, if laid out in a straight line, be too long." 4

Typical mall widths range from 30 to 40 feet, although wider areas that are 60 feet or more in width can be introduced to serve as courts or other special areas. One such area is the food court, which, according to the Urban Land Institute (ULI, 1999), should be treated as an anchor tenant so it can draw people past other shops. Its usual spot in the central area therefore puts the food court in a very good location for this purpose.

\section{Store Variations}

Store sizes vary dramatically, from large anchor stores taking up 200,000 square feet to kiosks, which are freestanding booths of 100 square feet or so placed in the trafficked area of a mall. Store depth of regular tenants is said to vary from 40 to 120 feet; store width of regular tenants varies as widely as store size.

The industry literature emphasizes that store types tend to vary by gross sales obtained per square foot, amount of rent paid per square foot and amount of space occupied. The literature also emphasizes that close watch should be made to assure tenants are not leased too much space. Certain tenant types should be leased so much space and no more; otherwise they will obtain "insufficient sales to justify the rent," (Vernor and Rabianski, 1993:150).

Summary figures from Dollars and Cents of Shopping Centers show that both sales and rent per square foot tend to decrease with store size and store types tend to fit into distinct size ranges. The graphs in Exhibit 1 demonstrate sales/rent/ size relationships for regional and super-regional shopping centers-for both ULI data and the database used in this study.

The graphs in Exhibit 1 show that merchandise types with smaller stores tend to maintain higher sales per square foot, and vice versa. For instance, for regional 
Exhibit 1 | Sales and Rent by Store Types

\section{Panel A: Regional Centers}

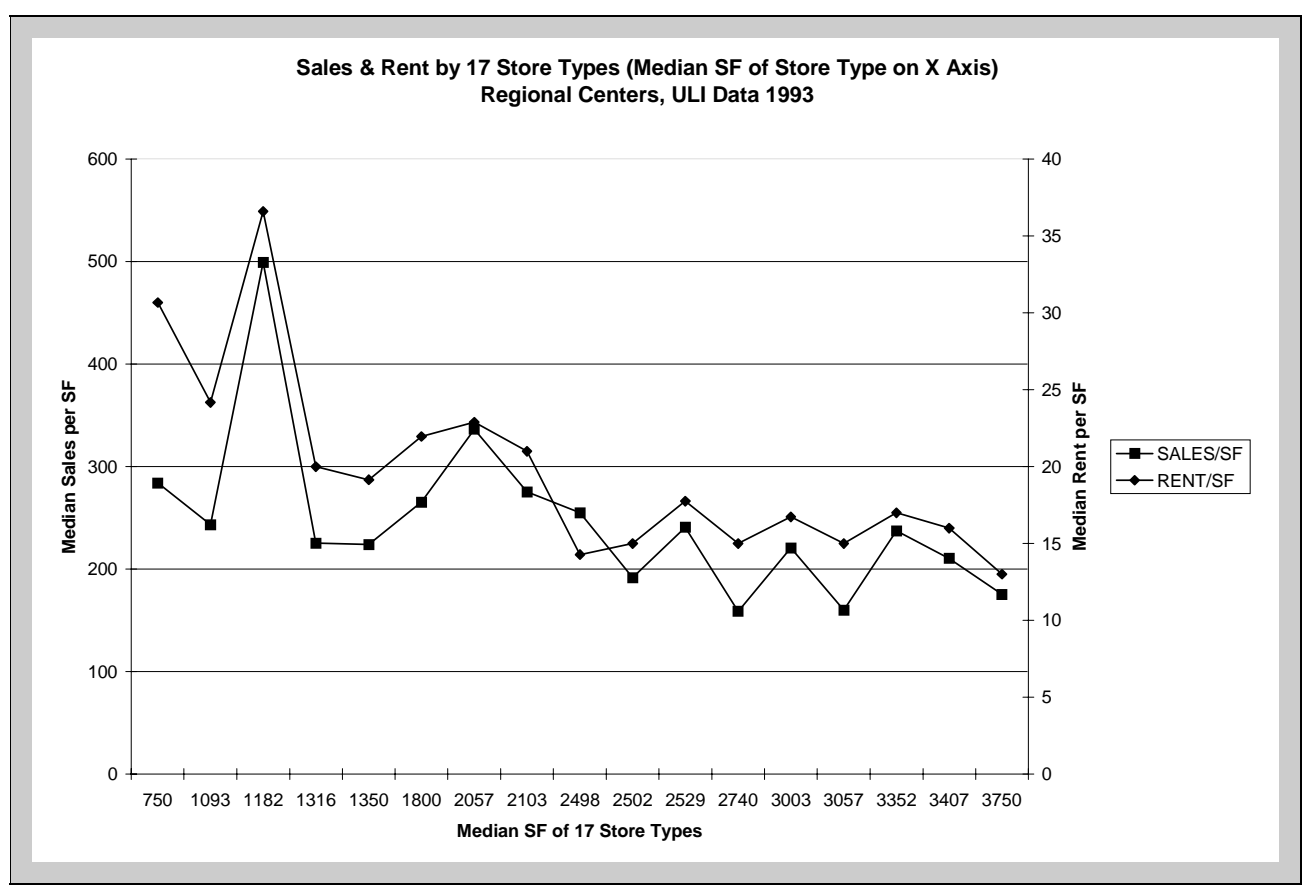

\section{Panel B: Super-Regional Centers}

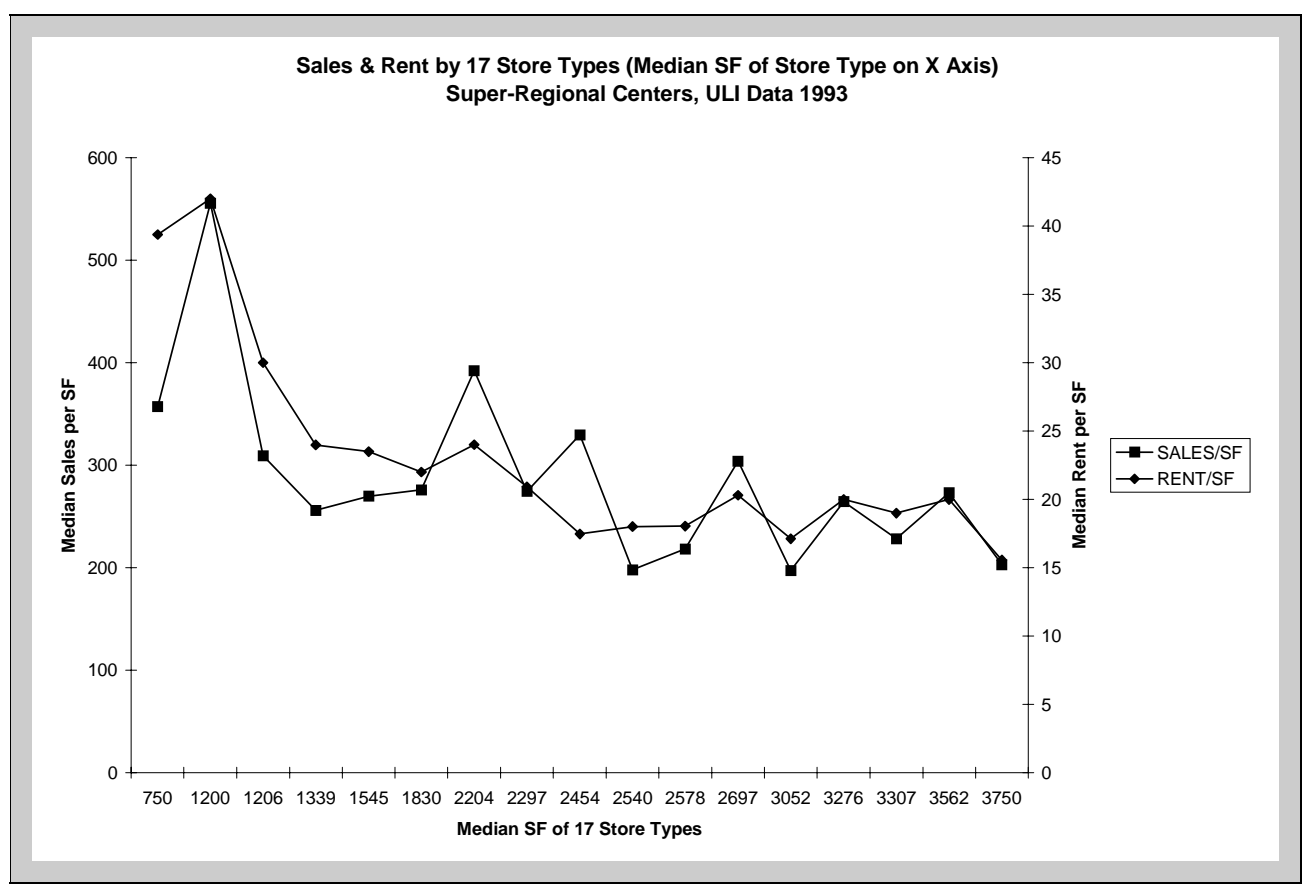

Source: Dollars \& Cents of Shopping Centers: 1993, Washington, DC: ULI. 
Exhibit 1 | (continued)

Sales and Rent by Store Types

\section{Panel C: Regional \& Super-Regional Centers}

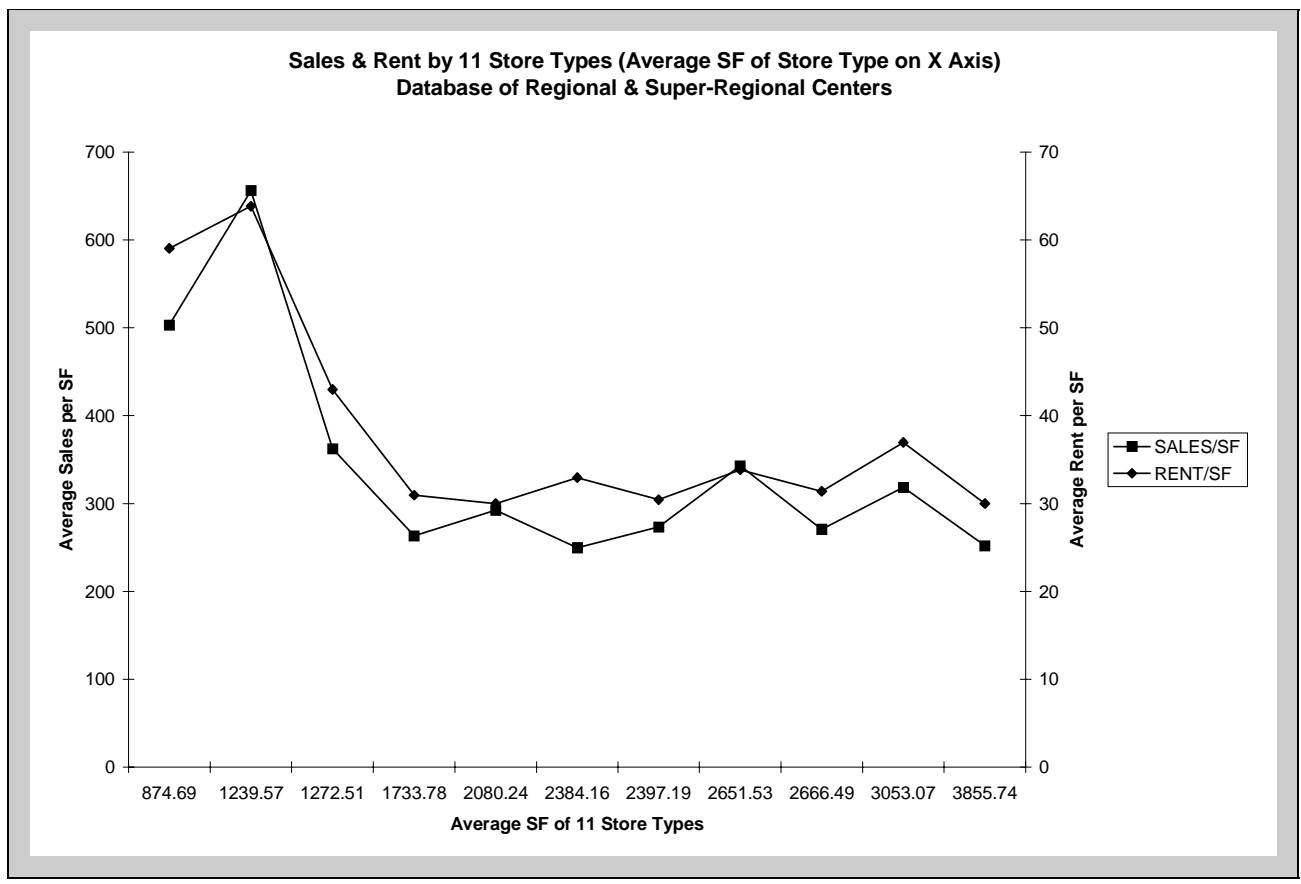

Source: Database, 1992.

centers, both jewelry and "candy and nuts" stores had relatively high per square foot sales, but maintained relatively small stores, while both women's apparel and toy stores had relatively low average per square foot sales but occupied larger stores. In addition to diminishing returns (sales) to scale, the graphs also show that rent tends to follow sales.

Two store location measures were deemed important and were mentioned in the industry literature: (1) "main" aisles versus "side" aisles (ULI, 1999); and (2) "central" aisles versus "side" aisles (Stambaugh, 1978). A simple view for a linear, regional mall would be that stores abutting the aisle between anchors located on opposite ends of the mall are the main aisles, while stores abutting aisles leading to exits are side aisles. Central aisles would be near the middle or in the area of the entrance to the food court. Side aisles are more peripheral than main aisles since exits are commonly some distance from the central area of the mall.

The best high trafficked areas, then, are between the anchors, but toward the middle-what professionals call "past the quarter point" of the length of the mall. Food courts are high trafficked areas. 
Measures of stores' distances to the mall's centers were made and added to the database. Exhibit 2 graphs these measures. Generally, results show definite trends for smaller store types to locate nearer mall centers and to generate higher sales per square foot there. The square footage-distance relationship is less erratic than the square footage-sales relationship. ${ }^{5}$

Industry literature is unanimous on the issue of anchors: anchors should be at opposite ends of the mall and, in the case of more than two anchors, should be equidistant from the center, the idea being that they draw shopper traffic through the mall and past non-anchor tenants. High trafficked areas, like main aisles or central aisles, should be reserved for impulse business, for instance fast food restaurants. Areas less trafficked, like side aisles close to entrances or exits, should be reserved for service tenants, such as banks, travel agencies, opticians, and dry cleaners, because they are destination stores. [Unlike anchor stores, which are also generally thought of as destination stores, service tenants are thought to have much less spillover effect on other mall tenants' sales. Drug stores and "high class" restaurants also fall into this category (ULI, 1999)].

\section{Application of Economic Theory to Optimal Store Location}

\section{Generally}

For bid rent theory, assume a shopping mall has a bounded linear region one unit in length with anchor stores at each end. The mall is symmetric about its center at distance $t=0$. There are $n$ types of mall tenants and each type of mall tenant $i$ has the following profit function:

$$
\begin{aligned}
P_{i}= & p_{i} \alpha_{i} u_{i}\left(A_{i}\right) d(t) A_{i}-C_{F i}-C_{M i} A_{i}-C_{L i} \alpha_{i} u_{i}\left(A_{i}\right) \\
& -C_{o i} \alpha_{i} u_{i}\left(A_{i}\right) d(t) A_{i}-r A_{i}
\end{aligned}
$$

where:

$P=$ Total profit;

$p=$ Price per unit of good sold;

$\alpha=$ Quantity of goods sold per purchasing customer visit;

$A=$ Store area;

$u_{i}\left(A_{i}\right)=$ Proportion of customer traffic per unit store area that purchases;

$d(t)=$ Density of customer traffic as a function of distance $t$ from the center;

$C_{F i}=$ Fixed costs unrelated to store area of sales volume (such as volume);

$C_{M i}=$ Quasi-fixed costs unrelated to sales volume per unit but dependent on store area (i.e., maintenance, utilities, tenant finish-out); 
Exhibit 2 | Store Distances to the Center of the Mall

\section{Panel A: Sales/SF Distance to Mall Center}

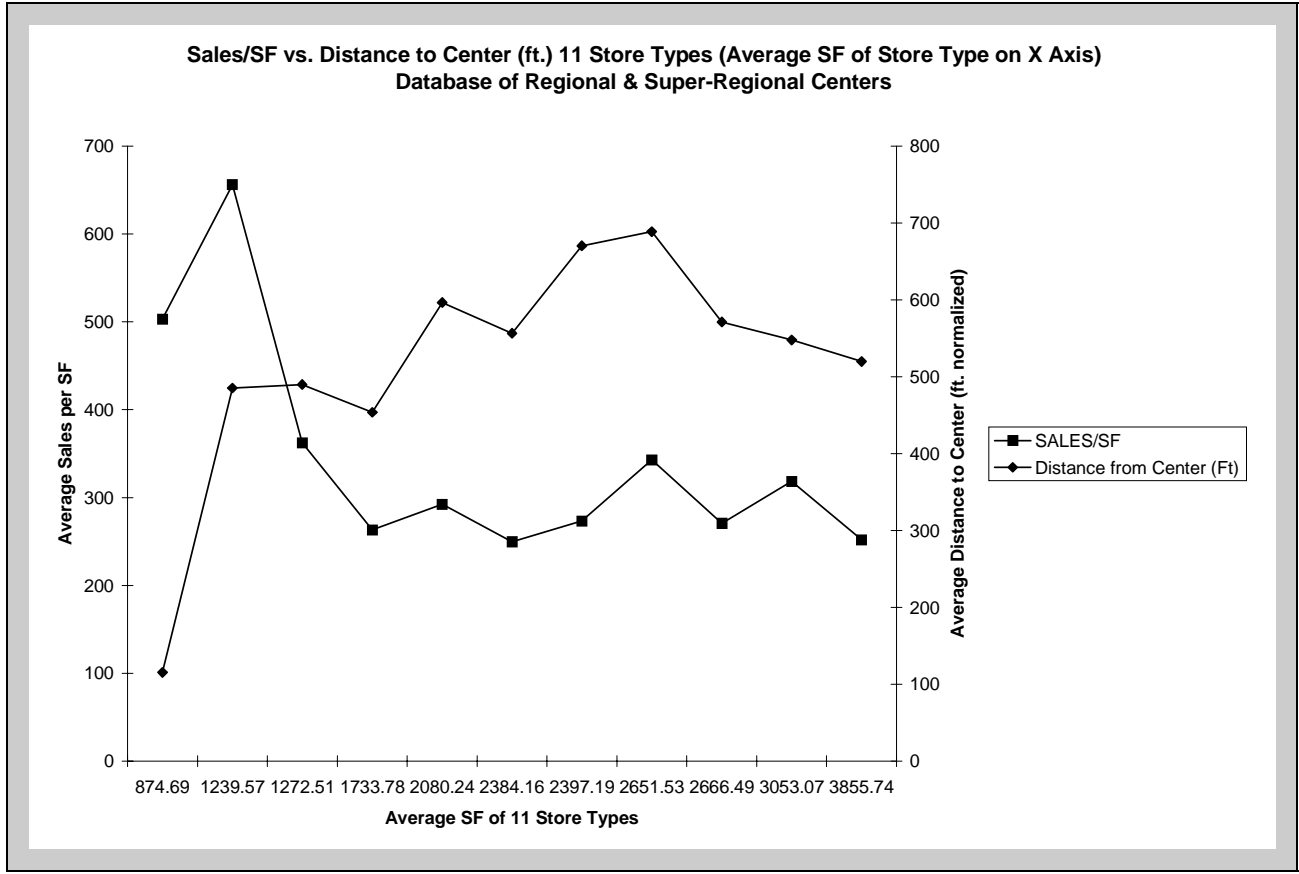

\section{Panel B: Rent/SF Distance to Mall Center}

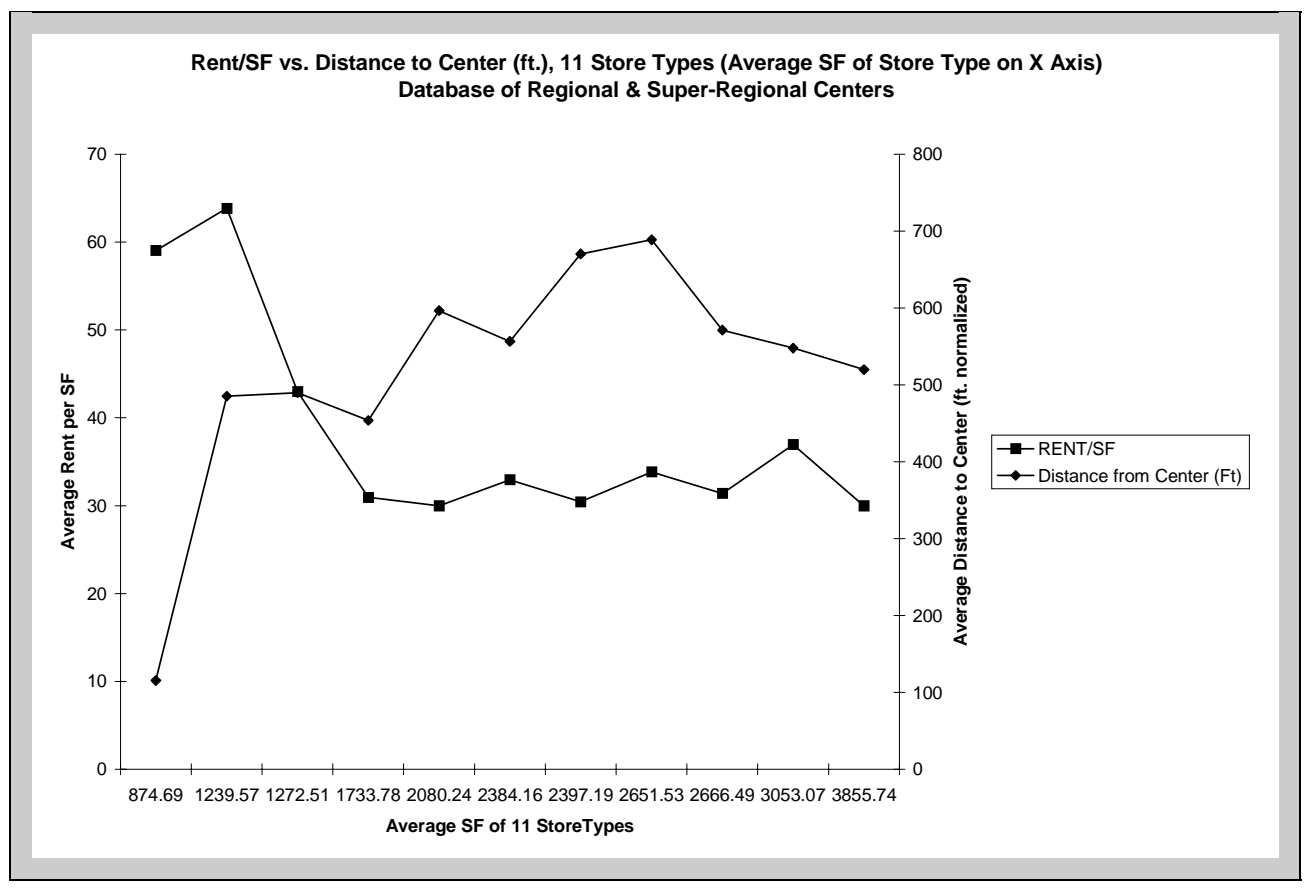

Source: Database, 1992.

\begin{tabular}{l|l|lll} 
JRER & $\mathrm{V} \circ \mathrm{I} .27$ & $\mathrm{~N} \circ .3-2005$ \\
\hline
\end{tabular}


$C_{L i}=$ Labor and operating costs, dependent both upon sales volume per unit and store area;

$C_{o i}=$ Cost of goods sold, dependent both upon sales volume per unit area and store area; and

$r=$ Rent. $^{6}$

The total number of purchases for a store area $A_{i}$ and a given level of traffic density, represented by the relationship $u_{i}\left(A_{i}\right) A_{i}$ exhibits decreasing returns to scale (i.e., $\partial u_{i}\left(A_{i}\right) A_{i} / \partial A_{i}>0$ but $\left.\partial^{2} u_{i}\left(A_{i}\right) A_{i} / \partial A_{i}^{2}<0\right)$. Thus stores have the incentive to limit size to a level where marginal revenue from adding an additional square foot of space is just offset by the marginal cost.

In terms of the profit function above, this is where (suppressing the subscript $i$ ):

$$
\begin{aligned}
\partial P / \partial A=0= & \alpha u(A) d(t)\left[p-C_{L}-C_{o}\right]-C_{M}-r \\
& +A\left\{\alpha d(t)[\partial u / \partial A]\left[p-C_{L}-C_{o}\right]\right\} \\
= & \alpha d(t)\left[p-C_{L}-C_{o}\right][u(A)+A \partial u / \partial A]-C_{M}-r \\
= & \alpha d(t)\left[p-C_{L}-C_{o}\right] \partial[u(A) A] / \partial A-C_{M}-r \\
\text { or } \quad & \left.\partial[u(A) A] / \partial A=\left(C_{M}+r\right) /\left[p-C_{L}-C_{o}\right] \alpha d(t)\right] .
\end{aligned}
$$

In addition to optimizing their consumption of space, store owners also want to locate at a distance $t$ from the center such that they can maximize their profit from operations. In a competitive market, excess profits are bid away by increases in land rent to the point where profit $P_{i}=0$. In terms of the profit function, this is where:

$$
\begin{aligned}
P & =0=\alpha u(\mathrm{~A}) A d(t)\left[p-C_{L}-C_{o}\right]-C_{F}-C_{M} A-r A \\
\text { or } \quad r & =\alpha u(A) d(t)\left[p-C_{L}-C_{o}\right]-C_{M}-C_{F} / A
\end{aligned}
$$

The relationships in Equations (1) and (2) may be combined to solve for the optimal space consumption $A^{*}$ and rent schedule $r^{*}$ as a function of distance $t$ from the center. If $u$ is assumed to be $u(A) A=k_{1} A^{k 2}$, where $0<k_{2}<1$ represents decreasing returns to scale, then:

$$
\begin{aligned}
& \partial[u(A) A] / \partial A=k_{1} k_{2} A^{k 2-1}=\left(C_{M}+r\right) /\left[\left(p-C_{L}-C_{o}\right) \alpha d(t)\right] \\
& \text { and } \quad r=\alpha k_{1} A^{k 2-1} d(t)\left[p-C_{L}-C_{o}\right]-C_{M}-C_{F} / A
\end{aligned}
$$


solving for $A^{*}$ yields:

$$
A^{*}=\left[C_{F} / \alpha d(t) k_{1}\left(p-C_{L}-C_{o}\right)\left(1-k_{2}\right)\right]^{1 / k 2}
$$

and for $r^{*}$ yields:

$$
\begin{aligned}
r^{*}= & C_{F}\left[k_{2} /\left(1-k_{2}\right)\right]\left[\alpha k_{1}\left(1-k_{1}\right) d(t)\left(p-C_{L}-C_{o}\right) / C_{F}\right]^{1 / k 2} \\
& -C_{M}=C_{F}\left[k_{2} /\left(1-k_{2}\right)\right] / A^{*}-C_{M} .
\end{aligned}
$$

The comparative statics results of Equation (4) demonstrate that optimal store area $A^{*}$ decreases with increased density of customer traffic $d(t)$. Hence stores decrease in size as they locate closer to the mall center. Also, optimal store area $A^{*}$ decreases in size with increase in price per unit of good sold, $p$. This accounts for the relatively small size of jewelry stores and other luxury goods stores in the mall. On the other hand, $A^{*}$ increases with increases in fixed costs (i.e., overhead, $C_{F}$, labor costs, $C_{L}$, and costs of goods sold, $C_{o}$ ). Further significant comparative statics results with regard to Equation (3) are as follows: (1) $A^{*}$ decreases with an increase in $\alpha$, the quantity of goods sold per purchasing customer visit. All other things being equal, destination/service stores like dry cleaners, banks and shoe repairers need less space than other store types. (2) $A^{*}$ is independent of $C_{M}$, costs such as maintenance and utilities that are unrelated to sales volume per unit area but dependent on store area.

The comparative statics results of Equation (5) demonstrate that optimal rent $r^{*}$ increases with density of customer traffic $d(t)$. Hence store rent is highest at the center and drops off at a rate $1 / k_{2}$ with customer density. Optimal rent $r^{*}$ increases with an increase in price per unit of good sold, $p$ (again an intuitive result in luxury goods cases such as jewelry stores). This accounts for the relatively high rents for jewelry stores in the mall. But $r^{*}$ decreases with increases in fixed costs.

So, all other things being equal, increased expenses lessen the amount of rentbeing a residual sum - that can be paid. And $r^{*}$ increases with increases in $\alpha$, the quantity of goods sold per purchasing customer visit. Other things being equal, then, destination/service stores such as dry cleaners and banks pay higher rentthe relatively lower rent paid by these stores will be predominantly due to lower traffic density at those stores' locations.

The relationship between $r^{*}$ and $C_{M}$ (costs such as maintenance and utilities, unrelated to sales volume) is also inverse, as is the case with the relationship between $r^{*}$ and $C_{L}, C_{o}$ and $C_{F}$. However, $C_{M}$ is a $1: 1$ relationship while other costs vary at a rate $1 / k_{2}$. Relationships between $r^{*}$ and $d(t), p, C_{F}, C_{L}, C_{o}$ and $\alpha$ vary at a rate $1 / k_{2}$. Thus $C_{M}$, being unrelated to sales volume, varies at a different rate with $r^{*}$ than do sales-related costs. 
It should be noted that certain conditions are assumed, which may limit the applicability of the model. These include no inter-store externalities among tenants that may affect densities of customer traffic and probabilities of sales in more complex ways than under the model. There is perfect competition, i.e., tenants bid for space and location in a way that maximizes their profits (reaching zero profits in competition). Here the mall developer would not locate tenants in a way that maximizes overall profit at the cost of reducing any individual store's profits, or reduces rents for an individual store below what would have existed in perfect competition. $^{7}$

Another assumption made here is that customer density $d(t)$ is exogenous when it in fact is endogenous to the location and size of tenants. This could be handled by assuming an iterative process where a prior $d_{o}(t)$ is assumed, locations are allocated, and a new distribution $d_{1}(t)$ results. The process is repeated until it converges at a stable distribution $d^{*}(t)$ in equilibrium. This distribution is assumed to be known, a priori, and so the solution of the model represents a global optimum, not an optimum for only a specific distribution of customer traffic densities. The results would be affected only if $d(t)$ were not downward sloping with distance $t$ from the center.

\section{$d(t)$ is Downward Sloping}

There is significant evidence that $d(t)$ is downward sloping. The customer circulation study by Brown (1991) was particularly persuasive. The second circulation study (Sim and Way, 1989) and the general observations of Fisher and Yezer (1993) also showed the highest concentration of shoppers at the mall center and the tapering off of shopper concentration toward the anchors.

This density distribution can also be demonstrated by simulating customer traffic under a set of reasonable assumptions. Consider a linear shopping center with anchors at either end that have $w$ times the customer generating power of mall tenants. Assume customers can enter the mall anywhere along its length and that each customer makes $n$ visits to stores, whether for comparison or multipurpose shopping. Also assume these visits are random with respect to store type (i.e., store type has nothing to do with customer density along the mall). ${ }^{8}$

The probability of visiting a store is in proportion to its statistical customer generating power shown in Exhibit 3 as relative customer traffic. Exhibit 3 provides the pattern of customer density (i.e., the probable average number of customers passing by or visiting the store, for eight mall stores and two anchors, with anchor customer generating power equal to twice that of a mall store. The two anchors act as two additional mall tenants making for ten mall stores.) Note that $\partial d(t) / \partial t<0$ and $\partial d^{2}(t) / \partial t^{2}<0$. Different customer visitation assumptions will create different customer density relationships with distance from the mall center (visits remaining random). The result in virtually every case is a downward sloping customer density relationship with distance from the mall center. 


\section{Exhibit 3 | Pattern of Customer Density}

\section{Simulation of Customer Traffic Along Linear Mall}

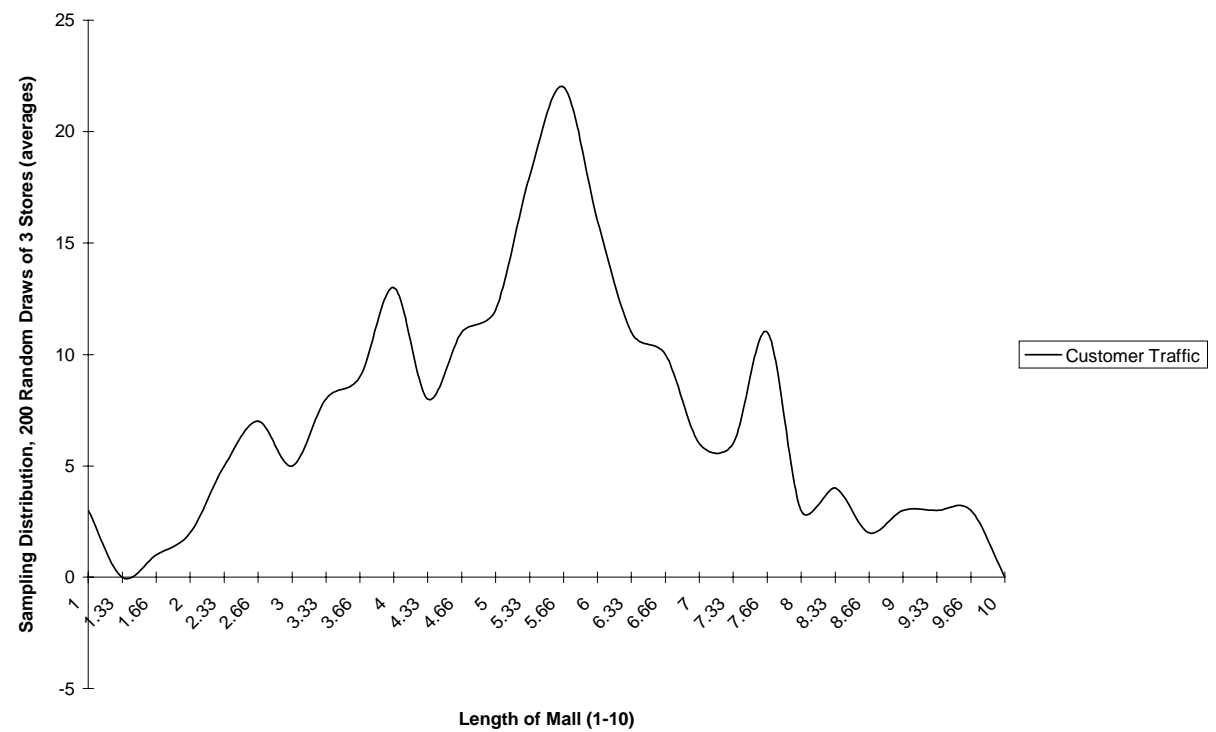

\section{Competition among Stores for Location}

So far a "closed city" bid rent model has been assumed for the location of stores in a shopping mall. Competition among store types necessitates an "open city", model where not all tenant types may be able to locate in a mall. A tenant type can be dominated by others to the extent that its bid rent curve is everywhere below that of a competitor or competitors.

Exhibit 3 graphs a sampling distribution of 200 draws of three stores (sample averages graphed). The parent population consists of twelve stores along a line as follows: 1, 1, 2, 3, 4, 5, 6, 7, 8, 9, 10, 10. The first two stores and the last two stores (1,1 and 10,10, respectively) represent two anchor stores, one at each of the opposite ends of the mall. The rest are non-anchor stores. Possible sample averages are: $1+1+1=3 \div 3=1 ; 1+3+2=6 \div 3=2 ; 3+5+10$ $=18 \div 3=6$. The simulation shows stores in the middle are more frequently visited. Sampling distributions of 2000 or more draws of three stores will more closely resemble normal distributions with thick tails.

Consider the above results for optimal space consumption and shape of the bid rent relationship for tenants with different characteristics and what it would mean for equilibrium of two or more tenant types. Following are the results from 
differentiating the optimal bid rent relationship in Equations (4) and (5) with respect to distance from the center $(t)$ :

$$
\begin{aligned}
\partial A^{* / \partial t}= & \left(\partial A^{*} / \partial d^{*}\right)(\partial d / \partial t)=-A^{*}(\partial d / \partial t)(t / d)(1 / t) \\
= & -\left(A^{*} / t\right)(\partial d / \partial t)(t / d) \\
((\partial d / \partial t)(t / d)= & \text { elasticity of } d \text { with respect to } t) . \\
\partial r^{* / \partial t=} & \left(\partial r^{* / \partial d}\right)(\partial d / \partial t)=\left(-C_{F} K_{2}\right) /\left(1-K_{2}\right) A^{* 2} \\
& (-A / d)(\partial d / \partial t)(1 / d) \\
= & \left(-C_{F} K_{2}\right) /\left(1-K_{2}\right) A^{*}(\partial d / \partial t)(1 / d) \\
= & -C_{F} K_{2} /\left(1-K_{2}\right) A^{* 2}\left(\partial A^{*} / \partial t\right) .
\end{aligned}
$$

Let $\Gamma=-C_{F} K_{2} /\left(1-K_{2}\right) / A^{* 2}\left(\partial A^{* 2} / \partial t\right)$, and the store types in the shopping center $\Gamma_{1}, \Gamma_{2}, \Gamma_{3}, \ldots \Gamma_{n}$. If $\Gamma_{1}>\Gamma_{2}$, then it implies store type $\Gamma_{1}$ will have higher rent. Also, $\partial^{2} r / \partial t^{2}<0$ and the rent gradient for $\Gamma_{1}$ will be steeper than for $\Gamma_{2}{ }^{9}{ }^{9}$

Store types with high sales response to customer traffic, high-priced goods and lower costs (or high margins) will tend to have smaller stores and to locate close to the mall center, since they are able to bid the higher rent per square foot for the right and have the steepest bid rent curves. These store types include jewelry stores (high price per item) and the food court (high sales response to customer traffic). Those at the other extreme of sales response to density, with lower-priced goods relative to their costs (lower margins), will tend to locate at the periphery, near the anchors. Examples here would include family apparel and house-wares. The point of indifference between two store types would be the distance at which the rent for one store type equals that for the other type, or where $r_{1}^{*}=r_{2}^{*}$.

From Equation (5), to solve the relationship for the point of transition $t^{*}$ :

$$
\begin{aligned}
r^{*}= & R=C_{F}\left[k_{2} /\left(1-k_{2}\right)\right]\left[\alpha k_{1}\left(1-k_{2}\right)\right. \\
& \left.d(t)\left(p-C_{L}-C_{o}\right) / C_{F}\right]^{1 / k 2}-C_{M} \\
= & C_{F}\left[k_{2} /\left(1-k_{2}\right)\right] / A^{*}-C_{M} \\
= & \left(C_{F} / 1-k_{2}\right)^{(k 2+1 / k 2)} k_{2}\left(\alpha d(t) k_{1}\left(p-C_{L}-C_{o}\right)\right)^{1 / k 2}-C_{M}
\end{aligned}
$$

Hence, $R(t)^{(i)}=\theta(t) \Gamma_{i}^{1 / k 2}-C_{M}$, where $\theta(t)=\left(C_{F} / 1-k_{2}\right)^{(k 2+1 / k 2)} k_{2}\left(\alpha d(t) k_{1}\right.$ $\left.\left(p-C_{L}-C_{o}\right)\right)$ and $\Gamma_{i}$ denote store types, as before. 
Choosing $\Gamma_{1}>\Gamma_{2}$, then $R(t)^{1}=R(t)^{2}=\theta(t)\left[\Gamma_{1}^{1 / k 2}-\Gamma_{2}^{1 / k 2}\right]$. This result holds for all variables in $A^{*}$, except $k_{2}, C_{M}$ and $C_{F}$. The $k_{2}$ parameter is interpreted as being different for store types and so a separating equilibrium occurs. The $k_{2}$ parameter is the proportion of customer traffic per unit store area that purchases. Differentiating store types this way creates bid rent equlibria. Stores more sensitive to customer volume go to the center and those not so sensitive locate at the periphery.

\section{Empirical Tests of the Bid Rent Model of Store Location}

According to the relationships in Equations (4) and (5) (between equilibrium rent and store size and distance from the mall center for various characteristics), the following models are suggested: ${ }^{10}$

$$
\text { Rent }(r)=f\left(p_{i}, \alpha_{i}, A_{i}, u_{i}\left(A_{i}\right), d(t), C_{L i}, C_{o i}, C_{F i}, C_{M i}\right) \text {, }
$$

where:

$\partial r / \partial t<0, \partial r / \partial d(t)>0, \partial r / \partial C_{L}, C_{o}>0, \partial r / \partial C_{F} \& C_{M}=0, \partial r / \partial p>0$, and $\partial r / \partial \alpha>0$, and where it is assumed $u_{i}\left(A_{i}\right) A_{i}=k_{i} A_{i}^{k 2}$, where $0<k_{2}<1$ (representing decreasing returns to scale).

Store Size $(A)=f\left(p_{i}, \alpha_{i}, A_{i}, u_{i}\left(A_{i}\right), d(t), C_{L i}, C_{o i}, C_{F i}, C_{M i}\right)$,

where:

$\partial A / \partial t>0, \partial A / \partial d(t)<0, \partial A / \partial C_{L}, C_{o}, C_{M}>0, \partial A / \partial C_{F}=0$,

$\partial A / \partial p<0$ and $\partial A / \partial \alpha<0$, where it is assumed $u_{i}\left(A_{i}\right) A_{i}=k_{i} A_{i}^{k 2}$, where $0<k_{2}$

$<1$ (representing decreasing returns to scale).

These models were estimated using collected data from the database. The following regression analysis empirically examined hypotheses derived from the bid rent model.

Hypotheses

1. Non-anchor store total rents and sales per square foot will decline with distance from the mall center for stores generally; non-anchor store total rents per square foot will decline at different rates by store type with distance from the mall center. 
2. Non-anchor store size will increase with distance from the mall center, both for stores generally and by the same rate for store the same types.

\section{The Shopping Center Database}

Tenant, lease and location data of non-anchor mall stores from nine regional and super-regional shopping centers located throughout the United States were supplied by two sources that required confidentiality. One thousand and twelve non-anchor tenants doing business in 1991 and 1992 were studied. Geographic diversity of the centers was as follows: Pacific (2) (San Francisco MSA; Los Angeles-Long Beach MSA); West North Central (1) (Minneapolis-St. Paul MSA); East North Central (1) (Chicago MSA); Southeast (2) (Memphis MSA; Miami MSA); Northeast (3) (Philadelphia MSA (2); Hartford MSA). All centers were enclosed, of contemporary design, comparable in amenities and occupancy (near 100\%) and competitive within the markets they served. They differed in size from 503,600 to $1,004,000$ square feet of gross leasable area. Six centers were single level, two had two levels and one had three levels.

Exhibits 4 and 5 set out descriptive statistics for the sample-for all the stores and by standard store types. ${ }^{11}$ Sales for non-anchor stores ranged from $\$ 34$ per

Exhibit 4 | Store Characteristics

\begin{tabular}{lcccr|}
\hline Variable & Mean & Std. Dev. & Min. & Max. \\
\hline Square Feet (SF) & 2,395 & 2,213 & 120 & 27,000 \\
Sales per Square Foot (\$ / SF) & 361 & 217 & 34 & 1,632 \\
Total Rent per Sq. Ft. (\$ / SF) & 36.64 & 25.17 & 5.83 & 277 \\
\hline
\end{tabular}

Exhibit 5 | Characteristics by Selected Store Type

\begin{tabular}{|lllrrrr|}
\hline Variable & Store Type & Observation Frequency & Mean & Std. Dev. & Min. & Max. \\
\hline SF & Gifts & $6.5 \%$ & 2,088 & 1,750 & 665 & 5,475 \\
SF & Women's shoes & $5 \%$ & 1,750 & 1,003 & 1,000 & 6,437 \\
SF & Women's apparel & $18 \%$ & 3,907 & 2,475 & 569 & 13,915 \\
SF & Jewelry & $6.2 \%$ & 1,301 & 648 & 472 & 4,278 \\
SALES \$/SF & Gifts & & 299 & 123 & 136 & 711 \\
SALES & Women's shoes & & 304 & 117 & 84 & 566 \\
SALES & Women's apparel & & 258 & 113 & 90 & 751 \\
SALES & Jewelry & & 676 & 276 & 213 & 1,433 \\
TRNT \$/SF & Gifts & 31 & 12 & 16 & 64 \\
TRNT & Women's shoes & 32 & 10 & 12 & 51 \\
TRNT & Women's apparel & & 28 & 17 & 6 & 77 \\
TRNT & Jewelry & 60 & 27 & 17 & 127 \\
& & & & & & \\
\hline
\end{tabular}


square foot per year for a minor anchor store to $\$ 1,632$ per square foot per year for a kiosk (a freestanding booth located in a main aisle). Differences in sales per square foot between malls seemed to depend on customer income in the market area [e.g., downtown San Francisco (highest) versus Memphis (lowest)]. Vacancy averaged $3.1 \%$ and was not a problem for any mall. Overall, national chain stores (businesses having stores located in at least a couple of states with a common name) made up $67 \%$ of the database, while local tenants (businesses originating from nearby) made up $37 \%$.

The data used in the empirical model represent 689 observations from eight of the malls, the triple-level mall being excluded because of difficulties in measuring location variables. Some lease data was deemed unusable and was excluded for one or more reasons. Mall stores were differentiated by length of lease, percentage and base rent, and location characteristics, including distance from the mall's center, as well as size and annual sales and rent per square foot.

Distance measures were the shortest walking distances to and from a mall's center and to and from the center point of each store's front side. A common definition for a mall's "center" was needed as was a normalization process by which distance measures between mall shops could be compared. A common sense definition of mall "center" was adopted borrowing from urban economic studies that located center points of metropolitan areas (e.g., Hohnson and Ragas, 1987; Pieser, 1987; Ihlanfeldt and Raper, 1990; and Coulson, 1991). Spatial patterns of mall store sales, rents and square footage was also viewed for each of the centers as part of the process.

Normalizing was conducted by dividing the distance measure by the square root of the mall area (non-anchor store area plus aisle and court areas). Significant differences in mall areas existed. Use of the same normalization procedure for all eight malls was deemed appropriate since three quarters of the malls had the same basic "I" shape.

\section{Tests of Hypotheses}

Consistent with bid rent theory, rents and size are assumed to be related to distance from the mall center (DISTANCE). Other tenant (TENANT) and (LEASE) variables shown in the literature to effect rent and size were added (CHN, TERM, SF and $S F 2$ ), as were tenant (TENANT) and location (LOCATION) variables hypothesized to be related to rent and size (COMP, EXIT, SAME and VACA). Rents and size are therefore assumed to be related to the four factor types DISTANCE, TENANT, $L E A S E$ and $L O C A T I O N$, where $R E N T_{j i}$ is measured on a per square foot basis for shopping center $j$ during the $i$ th time period.

$$
\begin{aligned}
& R_{E N T_{j i}}=f\left(\text { DISTANCE }_{j}, \text { TENANT }_{j}, \text { LEASE }_{j}, \text { LOCATION }_{j}\right) . \\
& \text { SIZE }_{j i}=f\left(\text { DISTANCE }_{j}, \text { TENANT }_{j}, L_{\text {LEASE }}, \text { LOCATION }_{j}\right) .
\end{aligned}
$$


The ordinary least squares (OLS) equations are estimated in the semi-log form ${ }^{12}$ for two models, and tests are made for heteroscedasticity following White (1980). The hypothesis that regression errors are homoscedastic is rejected for each of the equations (i.e., $p$-values less than .025), indicating weighted least squares (WLS) is appropriate. Examination of plots of residual errors of the independent variables shows that error variance is related to effective purchasing power of the market area of each shoppingcenter. ${ }^{13}$

Multicollinearity among individual variables of the regression equations was not a problem. ${ }^{14}$ Heteroscedasticity was eliminated after application of WLS regression to the models. ${ }^{15} \mathrm{R}$-square typically rises after application of WLS.

\section{Individual Stores, Rent and Size}

Research on determinants of mall store rents has been undertaken by Benjamin, Boyle and Sirmans in two articles $(1990,1992)$. Borrowing from their research, and adding location and other variables, two semi-log empirical models were estimated regressing non-anchor store rents and size in square feet on tenant, lease and location characteristics, as follows:

$$
\begin{aligned}
\ln \text { TRNT }_{i}= & \alpha_{\mathrm{o}}+\beta_{1} \text { CHN }_{i}+\beta_{2} \text { SF }_{i}+\beta_{3} \text { SF2 }_{i}+\beta_{4} \text { TERM }_{i} \\
& +\beta_{5} \text { COMP }_{i}+\beta_{6} \text { SAME }_{i}+\beta_{7} \text { CENTER }_{i}+\beta_{8} \text { VACA }_{i} \\
& +\beta_{9} \text { LOCATION }_{i}+e_{i} \cdot \\
\operatorname{lnSF_{i}=} \alpha_{\mathrm{o}}+ & \beta_{1} \text { CHN }_{i}+\beta_{2} \text { TERM }_{i}+\beta_{3} \text { COMP }_{i}+\beta_{4} \text { EXIT }_{i} \\
+ & \beta_{5} \text { SAME }_{i}+\beta_{6} \text { CENTER }_{i}+\beta_{7} \text { VACA }_{i}+\beta_{8} \text { TRNT }_{i} \\
+ & \beta_{9} \text { LOCATION }_{i}+e_{i} .
\end{aligned}
$$

Where:

TRNT: Total rent;

$C H N$ : $\quad$ A dummy variable $=1$ if a tenant is a member of a national or regional chain, 0 otherwise;

$S F: \quad$ Size in square feet;

$S F 2$ : $\quad$ Square feet squared;

TERM: $\quad$ Length of lease;

COMP: $\quad$ A dummy variable $=1$ if a tenant is a comparison of shopping store type, 0 otherwise;

SAME: $\quad$ Feet distance to the nearest same type store;

CENTER: Feet distance to mall center; 
VACA: $\quad$ Feet distance to nearest vacant store;

EXIT: $\quad$ Feet distance to nearest exit; and

LOCATION: Location dummy.

Following Benjamin, Boyle and Sirmans (1992), Guidry and Sirmans (1993) and Gatzlaff, Sirmans and Diskin (1994), dummy variables for location (LOCATION) were added to capture location characteristics of the malls.

$S F, S F 2, T E R M$ and $C H N$ were independent variables used in regression models estimated in Benjamin, Boyle and Sirmans (1992). Following that study, $S F$ was added as an independent variable to allow for economics of scale in leasing space to tenants large amounts of space; $S F 2$ was added because the effects of economies was not linear but decreased at a decreasing rate. According to Benjamin, Boyle and Sirmans (1992), tenants belonging to a national or regional chain $(C H N)$ were likely to generate higher sales and pay less rent. Additionally, tenants with longer lease terms (TERM) were likely to pay lower rents. Lower rent in these instances may represent a landlord's discount for lower default probability or greater tenant bargaining power. Higher sales result from name recognition of national and regional claims by consumers.

COMP was a dummy variable for comparison shopping store type. Eppli and Shilling (1995) hypothesized (but could not prove) that comparison stores were a second source of customer traffic generation for shopping centers (in addition to anchors) (see also, Mejia and Eppli, 2003). The most obvious comparison store types were chosen using a database supplied by Stillerman, Jones and Co. ${ }^{16}$ Comparison stores were men's apparel, jewelry, and men's and women's shoe stores.

Nearest distance to: (1) the mall center (CENTER); (2) a vacant store (VACA); and (3) the nearest same type store (SAME) were measured for all malls. ${ }^{17}$ Distances were measured as shortest walking distances within malls. SAME and $V A C A$ were added as location variables to pick up variations in sales and rents based on clustering/dispersion of store types and negative externalities associated with vacant stores, respectively. ${ }^{18}$

Multiple regression results using TRNT and $S F$ as dependent variables are summarized in Exhibits 6 and 7, respectively. The effects of distance from the shopping mall's center (CENTER) on total rents per square foot (TRNT) are negative and significant; the effects of distance from the mall's center on store size $(S F)$ is positive and significant. This is consistent with the expectations of a bid rent process. Non-anchor stores successfully bidding for location have higher rents the closer they locate to the mall's center. An approximate 4\% increase in rents is expected for every 100 feet closer to the mall's center a store locates. ${ }^{19}$ As expected, factor substitution occurs and square footage of stores $(S F)$ increases significantly at a decreasing rate $(S F 2)$, with increases in rents. ${ }^{20} \mathrm{CHN}$ was insignificant in the TRNT regression, and so does not contradict the finding of 
Exhibit 6 | Non-anchor Store Total Rent per Square Foot Regressed on Distance, Tenant Lease and Location Characteristics (semi-log functional form; weighted)

\begin{tabular}{lcrll|}
\hline Variable & Coefficient & \multicolumn{1}{c}{ T-Ratio } & Prob. & Variance Inflation \\
\hline Intercept & 4.0884 & 54.315 & 0.0001 & 0.0000 \\
CHN & 0.0167 & 0.504 & 0.6147 & 1.0950 \\
SF & -0.0001 & -13.285 & 0.0001 & 7.7037 \\
SF2 & $0.0219 \mathrm{E}-7$ & 6.349 & 0.0017 & 1.1717 \\
TERM & -0.0298 & -0.517 & 0.6053 & 1.0934 \\
COMP & 0.0026 & 0.070 & 0.9442 & 1.1589 \\
EXIT & -0.0002 & -1.815 & 0.0700 & 1.2744 \\
SAME & 0.0002 & 1.232 & 0.2183 & 1.5860 \\
CENTER ${ }^{a}$ & -0.2436 & -5.315 & 0.0001 & 1.4146 \\
VACA & -0.0003 & -2.255 & 0.0245 & 1.4336 \\
Mall Dummy Variables ${ }^{b}$ & 0.5544 & 10.104 & 0.0001 & 2.1544 \\
& -0.3904 & -6.586 & 0.0001 & 2.0544 \\
& -0.0804 & -1.465 & 0.1433 & 2.0204 \\
& -0.5443 & -9.120 & 0.0001 & 2.0705 \\
& -0.3863 & -5.816 & 0.0001 & 2.0810 \\
& -0.1769 & 2.986 & 0.0029 & 2.5006 \\
& -0.3814 & -6.340 & 0.0001 & 2.0302 \\
Note: $N=689 ;$ Adj. $R^{2}=.6804 ;$ and F-Value $=92.555$. & & 2.0262 \\
a Normalized & -0.2672 & -4.912 & 0.0001 & \\
bocational dummies & & & & \\
\hline
\end{tabular}

Benjamin, Boyle and Sirmans (1992) that chain stores generally have better credit and receive a rent discount from landlords for lower default probability. A positive significant coefficient for $C H N$ in the $S F$ regression is of course expected.

TERM was negative and significant in the TRNT regression and positive and significant in the $S F$ regression. According to Benjamin, Boyle and Sirmans (1992), this finding suggests longer leases may be appropriate. Thus, larger stores farther from the mall center would reasonably be more likely to have longer leases.

$S A M E$ was negative and insignificant in both the TRNT and $S F$ regressions. VACA was negative and insignificant in the TRNT regression and insignificant in the $S F$ regression. COMP and EXIT were both positive and insignificant in both regressions (although EXIT was significant at the 10\% level).

Regression results of these last four variables suggest two processes. Significant results for VACA and EXIT (at the 10\% level) reflect lower rent levels and larger 
Exhib it 7 | Non-anchor Store Size per Square Foot Regressed on Distance, Tenant Lease and Location Characteristics (semi-log functional form; weighted)

\begin{tabular}{lcrll|}
\hline Variable & Coefficient & T-Ratio & Prob. & Variance Inflation \\
\hline Intercept & 7.7451 & 54.168 & 0.0001 & 0.0000 \\
CHN & 0.3445 & 6.462 & 0.0001 & 1.0810 \\
TERM & 0.0019 & 3.153 & 0.0017 & 1.1717 \\
COMP & -0.0298 & -0.517 & 0.6053 & 1.0934 \\
EXIT & 0.0003 & 1.773 & 0.0767 & 1.2478 \\
SAME & 0.0002 & -0.766 & 0.4438 & 1.1520 \\
CENTER ${ }^{\mathrm{a}}$ & 0.1931 & 3.478 & 0.0005 & 1.6223 \\
VACA & -0.0003 & -1.364 & 0.1729 & 1.4785 \\
Mall Dummy Variables ${ }^{\mathrm{b}}$ & -0.0321 & -0.348 & 0.7280 & 2.1058 \\
& -0.1869 & -1.907 & 0.0569 & 1.9217 \\
& -0.0517 & -0.567 & 0.5711 & 1.9509 \\
& -0.1339 & -1.195 & 0.2324 & 1.7950 \\
& -0.3786 & -3.542 & 0.0004 & 2.0810 \\
& 0.0587 & 0.562 & 0.5746 & 2.5006 \\
& -0.0188 & -0.175 & 0.8611 & 2.0302 \\
& -0.2474 & -4.238 & 0.0001 & 1.9182 \\
\hline Note: $N=689 ;$ Adj. $R^{2}=.3573 ;$ and F-Value $=24.901$. & & \\
${ }^{a}$ Normalized & & & & \\
b Locational dummies & & & & \\
\hline
\end{tabular}

stores with distance from mall centers (vacancies are more plentiful at the peripheries). Results of $C O M P$ and SAME show a lack of overall clustering among stores of the same type. ${ }^{21}$

\section{Store Types}

The bid rent model developed here is further illustrated by focusing on store types rather than individual stores (i.e., Alonso's "families of bid rent curves"). Readily noticeable are the following: (1) different rates at which store type rents decline with distance from the mall center; (2) different intercepts at which store type rents begin to decline; and (3) a constant factor-substitution-generated rate of increase in the size of store types with distance from the mall center.

Rents. Rents per square foot were regressed against stores' (normalized) distances from the mall center and the store type dummies to measure how rents per square foot for store types varied with distance from the center. Results are reported in Exhibit 8. Exhibit 9 is a graph of the response curves representing average rents 
Exhibit 8 | Rent Variation by Store Type with Distance from Center

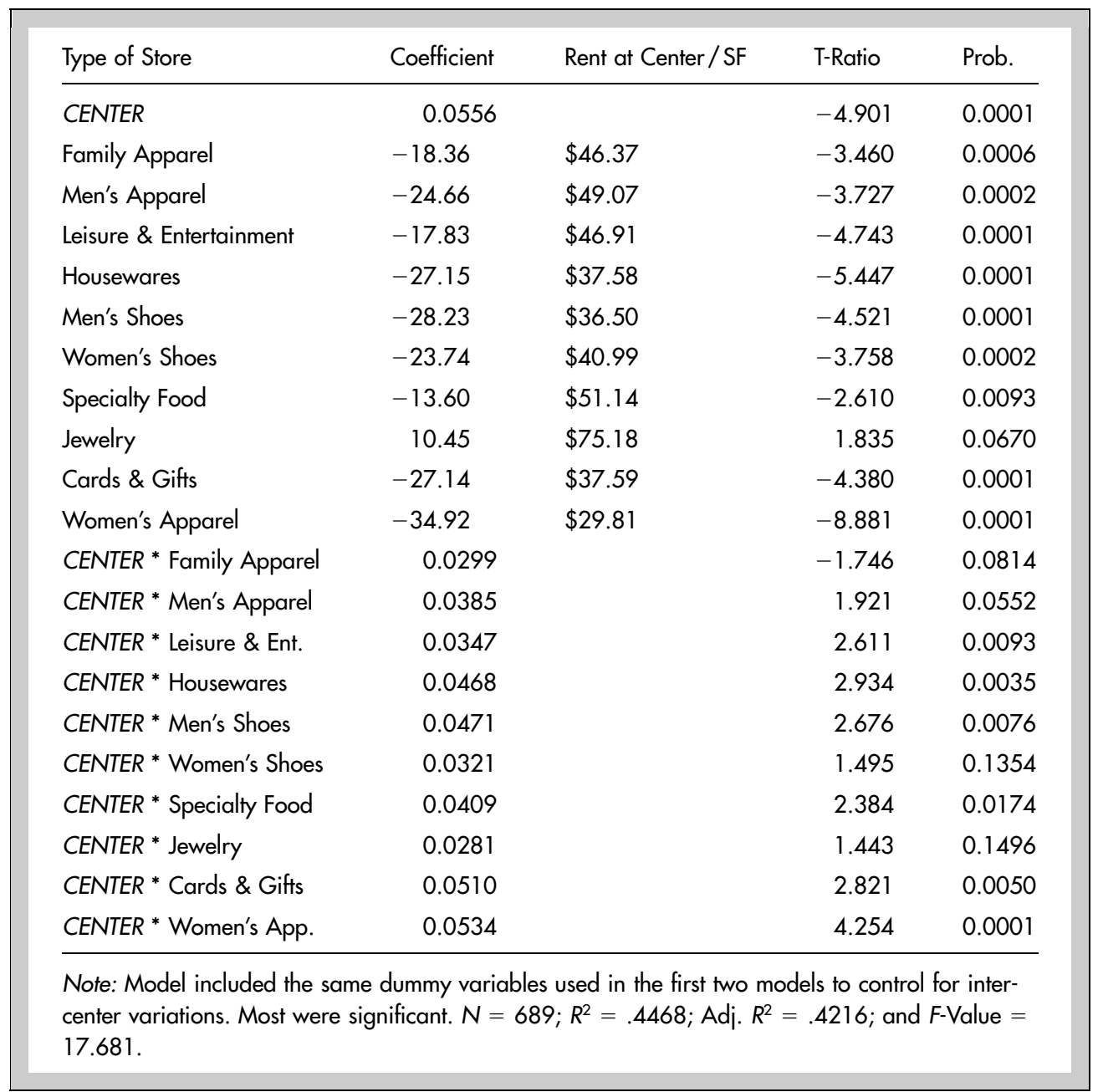

of store types with distance from the mall center. ${ }^{22}$ The curves reflect average rent paid by store types at various distances from the mall center. Store types paying rent at the center have steeper response curves and vice versa.

Size. To measure how square footage for store types varies with distance from the mall center, square footage was regressed against store (normalized) distance to the center and the store type dummies. Results are reported in Exhibit $10 .{ }^{23} \mathrm{~A}$ graph of these response curves, representing average square footage by store type with distance to the mall center, is presented in Exhibit 11. The response curves indicate how store types expand and contract with changes in location relative to 
Exhibit 9 | Average Rents of Store Types with Distance from the Mall Center

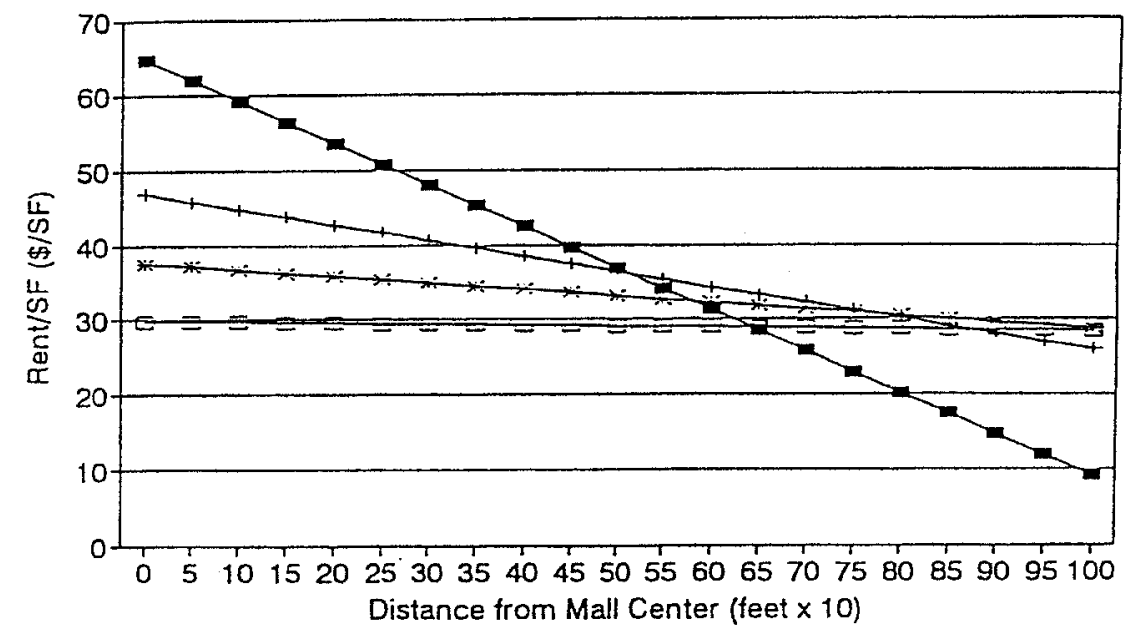

Exhibit 10 | Size Variation by Store Type with Distance from Center

\begin{tabular}{lcrrr} 
Type of Store & Coefficient & Size (SF) at Center & T-Ratio & Prob. \\
\hline Intercept (Fast Food) & & 666.75 & 68.339 & 0.0001 \\
CENTER & 1.0004 & & 2.927 & 0.0035 \\
Family Apparel & $2,132.22$ & 10.264 & 0.0001 \\
Men's Apparel & $1,673.43$ & 7.641 & 0.0001 \\
Leisure \& Entertainment & $1,593.14$ & 9.251 & 0.0001 \\
Housewares & $1,438.47$ & 6.403 & 0.0001 \\
Men's Shoes & $1,702.73$ & 7.967 & 0.0001 \\
Women's Shoes & $1,391.80$ & 5.526 & 0.0001 \\
Specialty Food & 931.54 & 2.828 & 0.0043 \\
Jewelry & 932.44 & 2.862 & 0.0043 \\
Cards \& Gifts & $1,512.95$ & 7.018 & 0.0001 \\
Women's Apparel & $2,720.31$ & 15.121 & 0.0001 \\
\hline
\end{tabular}

Note: Model included the same dummy variables used in the first two models to control for intercenter variations. Most were significant. $N=689 ; R^{2}=.3461$; Adj. $R^{2}=.3303$; and F-Value $=$ 21.922 . 
Exhibit 11 | Average Square Footage by Store Type with Distance to the Mall Center

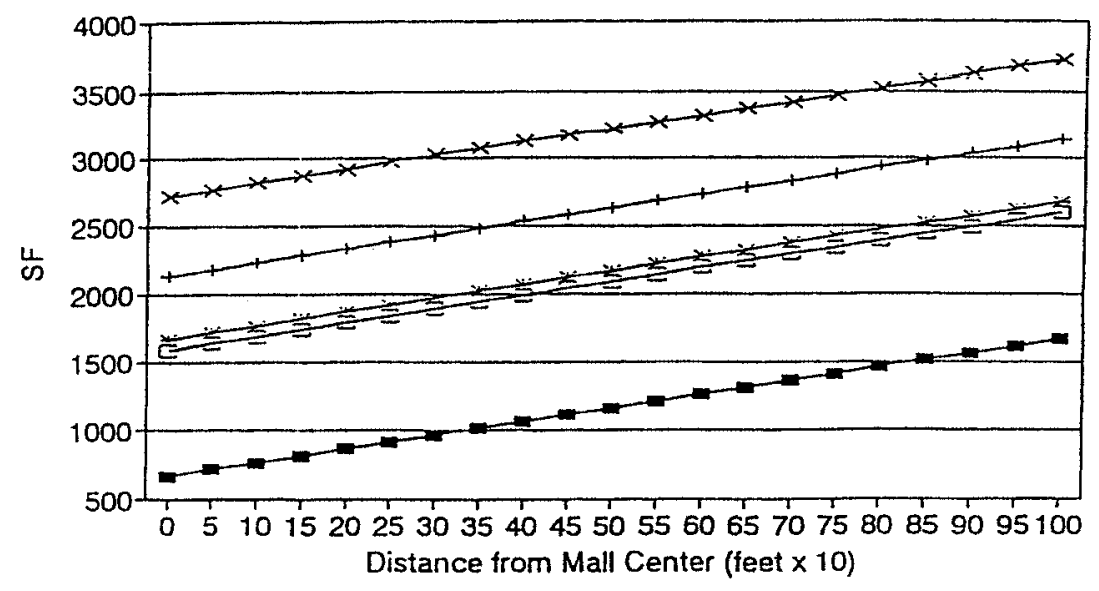

$\begin{array}{ll}\rightarrow \text { Fast Food } & \rightarrow \text { Family Apparel } \rightarrow-\text { Men's Apparel } \\ =\text { Leisure } & \rightarrow \text { Women'Apparel }\end{array}$

the mall center. The slopes are positive and constant, so all store types can be expected to increase in size at about the same rate with distance from the mall center.

\section{Conclusion}

Alonso's (1964) original model of firm location considered both business volume and transportation costs in determining location relative to a city center. Here business volume is a function of customer traffic density, and there are no transportation costs. Stores (firms) can increase sales depending on such parameters as quantity of goods sold per purchasing customer visit $(\alpha)$, price per unit of good sold $(p)$ and proportion of customer traffic per unit store area that purchases $(u(A))$. Costs are both fixed (unrelated to both sales volume and areas) and variable (varying with both area and sales volume).

The shopping center model depends on a downward sloping customer density function $(d(t))$ from the mall center. Empirical evidence from customer circulation studies and the general observations of Fisher and Yezer (1993) both support this requirement. Competition for store location was demonstrated theoretically for both "closed" city and "open" city models. Store area and proximity to the mall center were shown to be affected by such parameters as sales response to customer density $(u(A))$, price of goods $(p)$, low cost (or high margins) and quantity of goods sold per purchasing visit $(\alpha)$. 
Store types such as jewelry stores, food court, family apparel and housewares are shown to fit the results of the model well. Rents and rent gradients are shown to vary to demonstrate the bid rent process among store types. Also distances from the mall center are shown to vary by store type.

Insights into the theory can be applied to examine a problem that landlords routinely face, namely, how to fill a vacancy in a shopping center. In particular, we ask whether the landlord should add an additional outlet of one store type or another. This will depend on the stores' bid rent characteristics and distance from the mall center, especially its $\partial A^{*} / \partial t$ and $\partial r^{*} / \partial t$. Whichever alternative store type fits best will take the location. Since an "open" city context is used here, certain stores seeking to fill a vacancy may not be proper contenders for the spot.

The study confirms that non-anchor stores in a shopping center behave similarly to urban firms in a CBD. The process in the $\mathrm{CBD}$ is one of tradeoff between the desire for space and recognition of commuting (or transportation) costs (or distance from the mall center). In shopping centers it is the recognition of customer density effects on sales and costs that is important. Regressions indicate that total rents and store size for mall stores with respect to the mall center behave just as they do for urban firms with respect to distance from a city center. This was shown for both individual and market equlibria.

Future research should concentrate on refining the mechanism on just how shopping center space pricing and allocation operates in a perfectly competitive environment. Shopping centers provide an excellent example of Coase's Theorem that should be further studied. Although seemingly consistent with bid rent theory, future effort should examine expectations derived from agglomeration theory and the interaction of agglomeration theory with bid rent theory. Empirical tests of the bid rent model for shopping centers could use some improvement. Finally, some improvements in data measurement and methodology should also be considered.

\section{Endnotes}

1 According to Arnott, Anas and Small (1998:1451):

"Agglomeration economies have resisted attempts to fully understand their microfoundations. This is illustrated by urban economists' lack of confidence in forecasting the effects of the communications revolution on urban spatial structure. On the theoretical side, we do not know the scale at which the various forces work or what kinds of equilibria the simultaneous interaction of many forces will produce, nor do we have reliable models of dynamic growth paths and random shocks. We also do not know which external economies will be internalized through private initiative. On the empirical side, despite the increasing sophistication of studies relating a firm's productivity to the size and industrial composition of the city in which it is located, we do not know the specific forces that produce these relationships, or just how the depend on industry mix, local public goods, or zoning." 
${ }^{2}$ Regional shopping centers in the U.S. range in size from 300,000 to 900,000 square feet of gross leasable area (GLA). Customer driving time for goods and services at regional centers is about 20 minutes; market areas extend about eight miles around the center and serve populations of more than 150,000. Super-regional centers are larger in GLA and serve a larger population (ULI, 1999: 8-11).

3 "Anchor" stores are most often large department stores, such as Sears, J.C. Penney, Dillard's, or Nordstrom in the U.S. There are always anchors for regional and superregional centers. Other classifications of tenants can be anchors, especially for other types of malls (ULI, 1999). The International Council of Shopping Centers (ICSC) lists anchors as national mass merchandise stores, conventional department stores, discount department stores and other types of anchors (ICSC, 1992). The basic idea is that anchor stores have customer drawing power. They are most often destinations for customers coming to the mall (Kimball, 1991).

${ }^{4}$ Nothing considered to be a representative inventory has ever been taken of shopping mall shapes. In his doctoral dissertation, Eppli (1992) collected shopping center data on 54 regional and super-regional centers. Of these 54 centers, 17 (31\%) were linear, 16 $(29 \%)$ were a "T" design, $15(28 \%)$ were an " $\mathrm{X}$ " design and $6(12 \%)$ were an "L" design.

5 The shopping center database describes how mall centers were located and how center distance measures were calculated.

${ }^{6}$ Part of this model was set out in Carter and Haloupek (2000: 38-39). The intent here is to give detailed explanations of how Alonso's (1964)model and the model proposed here differ. Alonso's theory of the firm was developed using businesses in a city where land use is a function of the tradeoffs between desire for space and costs of commuting or transport. The city in which firms locate is a circular CBD where jobs are located. Arnott, Anas and Small (1998) describe basic assumptions: "Land use in the simple monocentric model is efficient - that is, the equilibrium density pattern is Pareto optimal (Mirrles, 1972; and Fujita, 1989). This is basically because there are no externalities; land-use decisions are based on tradeoffs between desire for space and recognition of commuting costs, both of which are purely private. The need for commuting is exogenous in the model, so no agglomeration effects are present. Of course, these nice properties disappear in more realistic models with congestion, air pollution, neighborhood quality effects, and economies of agglomeration. . .."

Firms in the city maximize profits with respect to quantity of goods produced and sold and location. Derivation of the bid rent curve for individual firms follows a profit maximizing objective function. Profits remain after operating costs and rent are paid from the revenues of business volume:

$$
\begin{aligned}
\Pi & =V-C-R, \text { where } \Pi=\text { profits; } V \\
& =\text { volume of business (revenue) } C=\text { operating costs; and } R=\text { rent. }
\end{aligned}
$$

But in a profit maximizing equilibrium, where firms have zero economic profits, $\Pi$ $=0$ and $R=V-C$. Business volume, $V$, depends on location, $t$, and size of the site, $q$, i.e., $C=C(V, t, q)$. Rent is determined by site size, $q$, times site rent at that location, $P(t)$ (i.e., $R=P(t) q)$. 
As distance from the city center increases, revenue from sales volume decreases at an increasing rate (i.e., the revenue function is convex from below). Overall operating expenses consist primarily of transportation costs that increase with distance from the city center. Operating costs are also affected to a lesser extent negatively because sales volume decreases with distance from the city center. Since revenue decreases and operating costs increases with distance, rent (bid rent) must decrease for the level of profits to remain constant $(R>0 ; \Pi=0=V-C-R ; R=V-C)$. The negative slope of a firm's bid rent curve is:

$$
d p / d t=\left(V_{t}-C_{v} V_{t}-C_{t}\right) / q
$$

where $V_{t}$ is the marginal revenue lost from moving an additional distance $d t$ away from the center; $C_{v} V_{t}$ is the indirect decrease in operating costs arising from the decrease in the volume of sales; $C_{t}$ is the marginal increase in operating costs arising directly from movement $d t$; and $p$ is the real bid by a firm at each location, $t ; V t$ is negative and $C t$ is positive, but $C t$ preceded by a minus sign is negative. $C v V t$ is negative, but preceded by a minus sign is positive. $C v V t$ is the decrease in operating expenses accompanying a decrease in volume and is less than the sales volume decrease (i.e., $\left.V_{t}>C_{v} V_{t}\right)$. Change in the real bid is equal to the change in the business volume less the changes in operating costs, divided by the unit of size so as to obtain a per-unit-of-land figure. The slope is such that savings in rent are equal to business lost plus increasing costs. Textbook examples often assume revenue will be the same throughout the city and bid rent curves are negatively sloped only because transportation costs increase with distance to the city center (e.g., DiPasquale and Wheaton, 1996: Chapter 3; and O'Sullivan, 2003: Chapter 8).

7 A result, of course, that would not make sense without Coase's Theorem.

${ }^{8}$ Customer travel costs between stores are considered negligible so distances between stores are not important. But costs incurred in "sampling," looking over and choosing goods at stores limits visits/purchases by customers. The simulation set out in Exhibit 3 assumes three stores per visit. Three stores per visit would seem a reasonable average. Stillerman, Jones and Company (1994) reports an average of three store visits per shopping trip for their survey sample of shopping centers.

9 Note that $K_{2}$ as well as the cost elements are store-specific.

10 Pursuant to the last section, revenue or sales $(p \alpha d(t) u(A) A)$ is a function of price $(p)$, customer density at some distance from the center $(d(t))$, proportion of customer traffic per store area that purchases $(u(A))$ and quantity of goods sold per purchase $(\alpha)$. Two types of costs vary with sales $\left(C_{L}\right.$ and $\left.C_{o}\right)$, and one is unrelated to either sales or area $\left(C_{F}\right)$.

11 The eleven store type categories into which all stores were divided are similar to those used by the Urban Land Institute (1993) and Eppli and Shilling (1995): jewelry, cards and gifts, women's apparel (including women's accessories), fast food, family apparel, men's apparel, leisure and entertainment, housewares, men's and boy's shoes, and specialty food.

12 This is consistent with the use of the semi-log form of in urban economic research, such as the negative exponential density functions used by Muth (1969) and Mills (1972) to 
describe how population density declines (i.e., at a decreasing rate with distance from a city center).

The function is, generally, for any variable $V, V=V_{o} e^{-\Gamma u}$, where $u=$ distance and $\Gamma$ describes the slope of the curve. Taking $\operatorname{logs}, \ln V=\ln V_{o}-\Gamma u, 0<\Gamma<1$ (e.g., $\Gamma$ $=0.9$ denotes a steeper curve than $\Gamma=0.2$ ).

Kennedy (1981) showed that estimation using a semi-log functional form with dummy variables results in a degree of bias in the estimated coefficients. In the present case, the adjustments suggested by Kennedy did not lead to changes that were economically meaningful.

The last three models are estimated using the linear form for convenience in making calculations.

${ }^{13}$ Heteroscedasticity often arises in the context of hedonic pricing models for residences when separate models are not developed for neighborhoods. A wilder variance for the error term results for higher priced properties that tend to sell over a broader range of independent variables (i.e., square footage, number of bathrooms, etc.) than low priced properties.

In the instant case, heteroscedasticity is a problem for much the same reason. Tenants with high rents and sales exist over a broader range of independent variable characteristics than tenants with low rent and sales. A shopping center in San Francisco is the equivalent of a house in an upper class neighborhood, while a shopping center in Memphis is the equivalent of a house in a lower class neighborhood. Only general shopping center market areas were noted (i.e., San Francisco versus Memphis, as opposed to researching median incomes of communities or actual market areas within cities) [e.g., Gatzlaff, Sirmans and Diskin (1994); and Guidry and Sirmans (1993) (who found that error variance was approximately proportional to shopping center size when malls were in same city)].

14 The conclusion of lack of multicollinearity is based on variance inflation factors, condition indices, and eigenvalue and tolerance limits procedures outlined by Belsley, Kuh and Welsh (1980. A check was also made for outliers/influential observations using the Belsley, Kuh and Welsh statistic DFFITS. Regression results were robust (i.e., outliers/influential observations deleted yielded comparable results).

15 Weighted least squares was applied using the standard practice of weighting by the reciprocal of the variance of the observations' error terms to stabilize the variance of $e$ and satisfy the regression assumption of homoscedasticity. A more involved but perhaps better method would be to weight observations by the effective purchasing power of the market area of the malls in which the stores are located (see, Gatzlaff, Sirmans and Diskin, 1994).

${ }^{16}$ Comparison shopping takes place more frequently at men's apparel, jewelry, and the men's and women's shoe stores than at other types of stores.

17 CENTER distances were normalized as follows: ((distance/square root of mall area) $\times$ 1000)). VACA and SAME distances were overall much shorter and were not normalized. One of the nine malls was triple level, not amenable to measurement, and so was excluded [see Carter (1999) for further details].

18 Comparison of results with varying functional forms for the TRNT hedonic model is set out in Carter (1999). It should be noted that the two models can be treated using application of two-stage least squares. In the simultaneous equations the case is one of over-identification, and $S F$ and TRNT are assumed endogenous. Consequently, improvement would be obtained by using a two-stage model. Initial two-stage least 
squares regression output showed estimates similar to those set out for both models. In the present model, a weighted instrumental variable methodology was not employed nor were the data transformed to properly apply the two-stage model (see Gatzlaff, Sirmans and Diskin, 1994). The hedonic model for TRNT was improved after correction for spatial autocorrelation in Carter and Haloupek (2000).

19 The results follow from interpreting the semi-log regression, having normalized distances for CENTER.

${ }^{20}$ This same effect of TRNT on SF and SF2 was found by Benjamin, Boyle and Sirmans (1992).

21 This was confirmed in Carter and Haloupek (2002) using the database described above and a model utilizing the $p$-median problem. Results of store-type dispersion are illustrated and explained on two dimensional maps of the shopping centers.

${ }^{22}$ Variation in rent for each store type over distance was obtained by adding the coefficients of the dummy variables to the intercept coefficient and the coefficient for CENTER. The response curves are not actual bid rent or demand curves: "(T)he hedonic interpretation of the gradient leads to further questions about the actual demand curve for location. Hedonic functions are not demand (or supply) curves, and the demand for location has not been calculated. That would require the instrumental variable estimation laid out in Epple (1987) and elsewhere," (Coulson, 1991).

${ }^{23}$ T-ratios for interaction terms were all insignificant, so a main effects model was used.

\section{References}

Alonso, W., Location and Land Use, Cambridge, MA: Harvard University Press, 1964.

Arnott, R., A. Anas and K. Small, Urban Spatial Structure, Journal of Economic Literature, 1998, 36, 1426-64.

Belsley, D., E. Kuh and R. Welsch, Regression Diagnostics, New York: John Wiley \& Sons, 1980.

Beddington, N., Design for Shopping Centres, London: Butterworth Scientific, 1982.

Benjamin, J., G. Boyle and C. Sirmans, Retail Leasing: The Determinants of Shopping Center Rents, Journal of the American Real Estate and Urban Economics Association, 1990, 18, 302-12.

_., Price Discrimination in Shopping Center Leases, Journal of Urban Economics, 1992, 32, 299-317.

Brown, S., Tenant Placement in Planned Shopping Centres: Implications of an Observation Survey, Journal of Property Research, 1991, 8, 179-87.

Brueckner, J., Inter-store Externalities and Space Allocation in Shopping Centers, Journal of Real Estate Finance and Economics, 1993, 7, 5-16.

Carter, C., The Nature of Store Location in Shopping Centers, PhD dissertation, School of Business, University of Wisconsin-Madison, 1999.

Carter, C. and W. Haloupek, Spatial Autocorrelation in a Retail Context, International Real Estate Review, 2000, 3:1, 34-48.

_., Dispersion of Stores of the Same Type in Shopping Malls: Theory and Preliminary Evidence, Journal of Property Research, 2002, 19:4, 291-311.

Coulson, N., Really Useful Tests of the Monocentric Model, Land Economics, 1991, 67: 3, 299-307. 
Darlow, C., Enclosed Shopping Centers, London: Architectural Press, 1972.

DiPasquale, D. and W. Wheaton, Urban Economics and Real Estate Markets, Englewood Cliffs, NJ: Prentice Hall. 1996.

Epple, D., Hedonic Prices and Implicit Markets: Estimating Demand and Supply Functions for Differentiated Products, Journal of Political Economy, 1987, 95:1, 57-80.

Eppli, M., Retail Leasing Behavior with Anchor Tenant Externalities, PhD dissertation, School of Business, University of Wisconsin-Madison, 1991.

Eppli, M. and J. Shilling, The Effects of Store Clustering in Regional Shopping Centers, Working paper, University of Wisconsin-Madison, 1995.

Fisher, J. and A. Yezer, Spatial Structure and Rents in Shopping Centers, Working paper, Indiana University, 1993.

Gatzlaff, D., G. Sirmans and B. Diskin, The Effect of Anchor Tenant Loss on Shopping Center Rents, Journal of Real Estate Research, 1994, 9:1, 99-110.

Guidry, K., and C. Sirmans, The Determinants of Shopping Center Rents, Journal of Real Estate Research, 1993, 8:1, 107-15.

Hohnson, M. and W. Ragas, CBD Land Values and Multiple Externalities, Land Economics, 1987, 63:4, 337-47.

Ihlanfeldt, K. and M. Raper, The Intermetropolitan Location of New Office Firms, Land Economics, 1990, 66:2, 182-98.

International Council of Shopping Centers, The Score: ICSC's Handbook on Shopping Center Operations, Revenues, and Expenses, New York: ICSC, 1992.

Kimball, W., Recent Trends in the Shopping Center Market, The Appraisal Journal, 1991, 382.

Maitland, B., Shopping Malls: Planning and Design, London: Construction Press, 1985, S. Brown, 1991, 179-180.

Mills, E., Studies in the Structure of the Urban Economy, Baltimore, MD: The Johns Hopkins Press, 1972.

Mulvihill, D., Q: How Should Stores by Mixed and Matched in Shopping Centers?, Urban Land, 1992.

Muth, R., Cities and Housing, Chicago: University of Chicago Press, 1969.

Northern I. and M. Haskoll, Shopping Centers: A Developer's Guide to Planning and Design, Reading: Center for Advanced Land Use Studies, 1977.

O’Sullivan, A., Urban Economics, Boston, MA: Irwin McGraw Hill, 2003.

Pashigan, B. and E. Gould, Internalizing Externalities: The Pricing of Space in Shopping Malls, Journal of Law and Economics, 1998, XLI: 1, 115-42.

Pieser, R., The Determinants of Nonresidential Urban Land Values, Journal of Urban Economics, 1987, 22, 340-60.

Rosen, S., Hedonic Prices and Implicit Markets: Product Differentiation in Pure Competition, Journal of Political Economy, 1974, 82:1, 34-55.

Sim, L., and C. Way, Tenant Placement in a Singapore Shopping Centre, International Journal of Retailing, 1989, 4, 4-16.

Stambaugh, D., Property Tenant Mix: How to Put it All Together, Shopping Center World, 1978, 7:4, 42-46.

Urban Land Institute, Dollars and Cents of Shopping Centers: 1993, Washington, DC: Urban Land Institute, 1993. 
_.., Shopping Center Development Handbook, Third edition, Washington, DC: Urban Land Institute, 1999.

Vernor, J., and R. Rabianski, Shopping Center Appraisal and Analysis, Chicago, IL: Appraisal Institute, 1993.

White, H., A Heteroscedasticity-Consistent Covariance Matrix Estimator and a Direct Test for Heteroscedasticity, Econometrica, 1980, 48, 817-38.

The authors acknowledge with thanks help from an anonymous referee. This paper was presented at the Asian Real Estate Society Meetings, Bejing, China, July 2000.

Charles C. Carter, Florida Atlantic University, Boca Raton, FL 33431 or charlesccarter@comcast.net.

Kerry D. Vandell, University of Wisconsin-Madison, Madison, WI 53706 or kvandell@bus.wisc.edu. 
